\title{
Integration of Information and Communication Technology (ICT) with pedagogy
}

\author{
Cynthia Dzimiri and Letwin Mapute \\ Department of Educational Foundations. Great Zimbabwe University. Zimbabwe
}

\begin{abstract}
The paper seeks to clarify the importance of integrating ICT in the learning and teaching processes. This includes the use of smart phones in schools where learners can research and send each other educational messages. Also importance of using computers in schools is highlighted and this promotes competence among school learners and with the outside world. The paper also looks at teacher competence in terms of using ICT. Advantages and limitations of using ICT in schools are discussed at the end of the paper before conclusion.
\end{abstract}

Keywords: Technology, pedagogy,e-learning,integration,communication

\section{Introduction}

Today's technologies are essential for teaching and learning in our society where knowledge is expanding rapidly. Schaefer (2010) refers to technology as information about how to use the material resources of the environment to satisfy human needs. In various sectors computer learning is now essential to successful functioning in society. Berns (2010) notes that along with television and cellphones, computers have revolutionalised communication. Computers enable users who have access to internet to get information from anywhere in the world. Today anyone with a smart phone can access the internet. Students use it to provide them with the information on their assignments. This is supported by Jung (2003) who noted that a variety of ICT can facilitate not only delivery of instruction but also learning process itself. He further noted that ICT can promote international collaboration and networking in educational and professional development.

\section{Background Of The Study}

Computers are not really new to education as they were used in the past for programmed instructions which involved reading information and answering questions (Haddad, 2003) for instance central technology in Education consortium for K12 teachers, school administrations and extended to adult literacy educators use video tapes and CD-ROM to help teachers to see how technology can be integrated into their work. These CDROMS contain video descriptions and demonstrations of how technology is used in the classroom. Video sequences are viewed by teacher focus groups who then discuss the strategies and techniques of classroom management (http://www.techknowlogical.org/TKC)

The community has also seen the need of information communication technology through the donations of computers in school to serve as educational tools as they are used by teachers in planning, scheming and power point presentations. The government has also donated some to various schools and the Jewel bank had a promotion in which it gave away computers to winning school.

However, the computer effectiveness as a tool for learning depends on how it is used by teachers and students as well as the software selected. To use these tools effectively and efficiently, teachers need visions of the technologies' potential opportunities to apply training and just in time support and time to experiment. Only then can teachers and students be informed and confident in their use of new technologies (Bowes, 2003). For instance, in the primary and secondary environment word processing and presentation software are used to enhance instruction. Microsoft word can also be used in schools. It is equipped with templates and wizards employed to create useful documents such as resumes, newsletters to parents on information about Annual General Meetings and school trips.

Jewel (2000) notes that the software processes information faster than writing by hand, other additional functions include word counting, spelling checking, dictionary foot noting and index generation. He further noted that a document format type size, line spacing margins and page length can be altered with minimum difficulty. Text is displayed in bullets and numbers which highlight important points. Simply the most time serving tool a teacher can have especially when writing reports, lesson planning and scheming.

Pacey (1999) also notes that a presentation program is a computer software package tailored for people who use it to give presentations normally in form of a slide show using the projector and computer. Some examples include Microsoft power point and $\mathrm{K}$ presenter. However Microsoft power point is used in primary schools to teach new ideas and concepts to pupils. Also Haddad (2003) asserts that power point presentations are used 
much more for practices and drills in irregular verbs and correct form of an adjective. Countable and uncountable contrasts are practised and viewed periodically. Games are also a good way to review and practice English (Perraton, Robinson and Creed, 2001).

Furthermore cell phones just like computers are teaching and learning tools. Students as they chat with others through FACEBOOK, TWITTER or SKYPE they exchange ideas, and the internet also promotes discussions among students and teachers.

\section{Uses of smart phones in school}

The cellular phone is an excellent example of technology that was developed for communication but now includes many features that relate to the internet. Gross (2010) asserts that portable wireless phones actually existed as far back as 1920s but were cumbersome and expensive and did not catch on with the general public. By pictures, access the internet, enable text messaging, play music and show video (Prichard, 2004). Thus individuals can access all the print, audio and videos material available on the internet through a cell phone. Sellion (2004) notes that music, memory cards and games are the major priorities to which cell phones are being used by pupils. The memory card can store information ranging from music to pictures. The pupils can also carryout calculations on their cell phones and above all can access the internet which has become the place to be as noted by (Gross, 2010).

The internet is closely aligned with many forms of entertainment and information including video games and portable devices such as cell phones, PDAS and IPADS. Siddiqui (2004) observes that televisions and movies were separate for many years, the internet now incorporate materials from all of them. The internet's interactive capabilities have taken media in a new direction. Schaefer (2010) indicates that previous media forms were usually one way, when people interact with the internet be it emailing or gaming or any of the many offers that the internet has spawned. They are in an active stage, that involves thinking and doing thus pupils can access all the educational material over the net through the use of a cell phone.

Email is a popular method of communication. One can access email on a computer, a mobile phone and other digital devices that have wireless (hawkblock unit. Blogspot). One can access his or her email from a lot of different locations. Teachers when they want to have the information from their resource teachers, can easily sent emails across with the push of button. Also the head when he or she needs to conduct a meeting with the teachers can simply send the emails, students as well can exchange assignment information with their colleges on email. However the disadvantage is, the email address could get hacked and confidential information can fall on wrong hands. It is also difficulty to make changes once the email has been sent and at times one can fail to interpret the message sent over the email and would need clarity as compared to verbal communication (hawkblock unit. Blogspot).

Telephone or fax are also used to communicate vocally over the entire world, thus in schools when heads or teachers want information on dates for sporting activities, workshops on staff development and seminars they can talk to someone, a method that serves time and cost effective as far as transport is concerned. Documents also can easily be sent to the other fax machine. The use of telephone however, is only effective when there is a good signal since it is hard to understand a person's voice if there is a bad signal across the phone.

Furthermore, devices like computers, encourage the use of video or video conferencing to communicate while being able to see each other (Gross, 2010). This enables one to clearly show what one will be trying to explain. When pupils see a video it becomes easier for them to understand the concepts. Also a lecturer or teacher can conduct a lesson whilst in the office and manage to get in touch with students from different areas through Skype. However, again if there is bad connection, the video will not be in very good quality.

When using cell phones, texting or sending messages to another phone it is a facility that is quick and easy (hawkblock unit. Blogspot). Pupils may send each other educational messages if there is a good signal and get the response there and there. As mentioned earlier by Gross (2010) that pupils can access the internet over the phone it has been noted that these pupils can be exposed to bad and good information due to high rate of accessibility to the internet website (Garura, 2010). While some pupils can establish social relations, like finding new partners through the FACEBOOK, others, can visit sites that promote teenage gambling. In view of this observation children need shrewd monitoring either by parents or school authorities. It is interesting to note that some existing literature about the internet use, have claimed that pupils may bump into pornography when doing their school homework (Fenry, 2008). These pornographic materials may affect their sensual feeling and thereby making pupils to be easy prey of unscrupulous individuals who are not considerate.

Other pupils by use of cell phones can access pornographic sites to entertain themselves and the internet is associated with cultural erosion Siddiqui (2004). Pupils are exposed to many cultures on the internet. Cultural fertilization is theoretically good but when viewed from a cultural imperialistic perspective, it becomes bad. One culture is suddenly relocated to the periphery. The internet is overwhelming as English medium. 
Barber (1995) has observed that those who want to participate fully must have proficiency in English as a language. For instance a high level governed panel in Japan recommended the adoption of English as the official language for the future (English imperialism, 2000). This is an example of a centre periphery dichotomy that may eventually function to reinforce the superiority- inferiority relationship when applied in pedagogical situations. Evaluated in terms of cultural imperialism if one language is marginalized through the internet, it only means that system of winner takes all is pedagogically disadvantageous in the learning process.

A substantial number of pupils however, tend to abuse cell phones. Abuse of cell phones is seen through the sending of messages, picture messaging and jokes during school business hours. Some pupils transmit nasty text messages as a form of bulling. This is supported by Sellion (2004)'s observation concerning addiction therapy. He says in part pupils are addicted to messages and compulsive checking of mobile phones. This compulsive checking of mobile phones, compromises the effective use of learning and teaching times. Music, memory cards and games are major priorities which cell phones are being used by pupils. Sellion (2004) notes that the memory cards can store information ranging from pornographic material, music and pictures if there is no adequate monitoring from parents concerning the websites that pupils access. The chatting on the internet can be disastrous in terms of moral conduct. Pupil can be exposed to social problems usually linked to acts of misbehaviour like more multiple partners whilst young.

\subsection{Computer use by schools and learners}

With the introduction of e-learning in schools, most schools found themselves purchasing quite a number of computers and some were even donated to them by the government. By so doing most primary schools in urban areas as well as some in rural areas are exposed to the use of multimedia technologies. However Kirschner and Selinger in Fenry (2008) observed that many pupils are more adept than their teachers in using a variety of technologies to acquire and transmit knowledge. The pupils tend to be prolific and fearless users of technologies to the extent that they can assimilate new software and hardware easily. In other words, the learners are light years ahead in the use of information communication technologies as noted by Fenry (2008) who refers to the learns as the next generation.

Studies have shown that quite a number of predators maybe on line on a daily basis (watchtower, 2009), these will be patrolling the internet chat rooms.

The entertainment which the learners obtain through the use of computers and their eager to explore the internet for educational and entertainment purposes result in them being the most computer users than the school (Barners, 2008). He also notes that alongside television and cell phones, computers have revolutionalised education practice since it needs computer literacy to access the internet. Dickens in Gross (2010) asserts that the main benefit of the internet is that it facilitates cheap and easy direct personal access, irrespective of distance, whether there is justification for the claim that it amounts to the death of distance is probably questionable but Gross in Barnes (2008) agrees that the ability to reduce the effects of distance can be significant. The use of emails enables pupils and teachers as well as schools to communicate virtually instantaneously almost everywhere on the planet. Barnes (2008) indicates that almost limitless quantity of data can be transferred within seconds, more sophisticated applications can support synchronous working on documents between pupils thousands of miles apart. Thus the majority of pupils are exposed to the use of computers for instance in urban areas where there are several internet cafes. Learners hence become the most users of computers as they will be using the computers for educational purposes. According to Siddiqui (2004:46) "a student who uses computers in school demonstrates improved motivation and enthusiasm for school work." Thus technology enhances student achievement by engaging and involving them. To young people the computer is totally engrossing, they learn without even realizing it, kindergartens discover the letters of their names, identifying shapes and learn to count while playing with well designed software.

Today a variety of ICT can facilitate not only delivery of instruction, but also the learning process itself. With the use of the internet learners can research various topics and obtain knowledgeable information. Fenry (2008) notes that by empowering, the new technology allows students to feel a pride of accomplishment when they view their output, be it a healthy formatted report, a colourful chat or a desktop published newsletter the students become active producers of knowledge whether they are sharing their findings with the world via a web page or with their classmates via Power Point presentation. The computers' forgiving nature, which allows even the worst errors to be easily remedied does wonders for sensitive young egos (Siddiqui, 2004)

Haddad (2003) asserts that computers allow students to develop the very same competences identified as essential for the modern workplace. He further argues that computer using students demonstrate greater problem solving and critical thinking skills compared to students in traditional classrooms. Also computers ensure students mastery. (Siddiqui: 2004) asserts that computers equipped with appropriate software for instance, instructional software which is an infinitely patient non judgmental one allows each student to proceed through a topic at his or her own pace until mastery is archived. 
Also, student can download movies that are educational and can enhance their achievement. Voice over the net as noted by Gross (2010) has a positive impact on the integration of ICT and pedagogy because sound can be sent over the internet, it is possible for pupils to talk to each other, and exchange ideas that are relevant to their studies. The Skype users also can call each other if both are talking through headphones connected to their computers. They can type their documents using the computer a most time serving tool that a learner can use and is reliable. Learners can as well send their research projects through email and lecturers mark and send them back to the learners. This serves a lot of time and expenses for travelling.

\subsection{Teacher competency in using ICT}

The effective use of education technology also requires teachers to have both the skills and a certain comfort level to make full use of what technology has to offer. As new concepts of learning have evolved Bowes (2003) notes that teachers are expected to facilitate learning and make it meaningful to individuals rather than to provide knowledge and skills. In regard to this, modern developments of innovative technologies have provided new possibilities to teaching professions, but at the same time have placed more demands on teachers to learn how to use these new technologies in their teaching. Robinson and Latchem (2003) assert that teachers continuously retrain themselves and acquire new knowledge and skills while maintain their jobs. ICT teacher training can take many forms. They can be trained how to use ICT or can be trained via ICT or ICT can be used as a core or complementary means to the teacher training process. Collis and Jung (2003) observe that pedagogies used by most teachers in Australia and New Zealand reflect a long tradition of learners centre theories of education. These theories require learning to be individualized and collaborative, experiential, building, or prior learning, self managed and cumulative, authentic and direct to higher order problem solving. The use of Information and Communication Technologies builds on, and extends this pedagogical approach (http://www.en.wikipedia.org/wiki/year200pedagogy). Pedagogies integrating ICT can do more than enhancing learning. ICT provides tools and environments that support interactive conceptual learning focused on construction and creating knowledge. Carlson and Gadio (2002) aver that those teachers who integrate ICT with pedagogy engage students in new dimensions in exploring and experimenting, thinking and working creatively, reflecting and planning, using feedback and self assessment, creating new Dimensions of knowledge, communicating with others, working interactively with local and global learning communities. Teachers play a crucial professional role in ensuring that the integration of ICT into pedagogies is educationally sound (Robinson and Latchem, 2003). They evaluate the appropriateness and effectiveness of available technologies, deciding when and how to use them with their students. In addition teachers integrating ICT into their pedagogies, select appropriate learning activities, tools and resources to motivate and engage, personalise learning, engage with diversity to support inclusiveness, develop ICT literacy, establish communities of learning and assess progress and evaluating teaching (Perraton, Robinson and Creed, 2001).

The effectiveness of integrating ICT with pedagogies depends on high levels of interactivity amongst and between students and teachers, and between students and the technologies they use. In teaching for conceptual development teachers use ICT to empower students to purposefully select activities, applications and modes of communication. They also gather and make electronic resources available to students for anytime access. Newman (2010) also notes that teachers should be equipped with the knowledge of ICT in order to use information from online sources, select and use learning objects to create learning activities and sequences, provide processing and presentation tools, engage in simulations, modelling and creative activities, encourage the use of games and programs that contextualise concepts, provide problem solving challenges and engage student with virtual objects and worlds.

In building learning communities Pacey (1999) mentions that, teachers use ICT to provide communication and collaboration tools such as chat, email, messaging, discussion forums, online meetings and video conferencing. In order to enhance learners' achievement teachers also use ICT to be part of broader communities. Pupils from wider part of the world can interact and exchange ideas. The teachers also support student participation in online collaborative projects for instance in a group chat pupils can share important information on their areas of study. ICT is also used by teachers to make learning activities, information courses and feedback available online anywhere and anytime, support students using online resources to share with other students and experts and also increase parent access to student's work.

Furthermore Jung (2001) postulates that in planning, programming, assessing and reporting teachers use ICT to align programs and resources with curriculum frameworks, store, retrieve and adapt teaching materials and approaches, facilitate informal and formal assessment. It provides students with more immediate feedback from teachers and their peers and track progress and record completion and achievement. Also learnercentred theories stress the importance of the relationship between the family, the school and the community as indicated by Jung ( 2001) who avers that communication enabled by the use of ICT facilitates this relationship. It provides new opportunities for parents to engage with teachers, learning programs and their children's progress. 
However, the following principles provide a framework for developing innovation pedagogies for learning on an online world and for evaluating their effectiveness. (icttaskforce @mceetya.edu.au) effective integration of ICT can transform pedagogy by empowering teachers to focus on student-centred, active and interactive learning, connect with learner expectations, experiences and needs, provide opportunities for students to create, construct and communicate knowledge as well as, develop critical and ethical understandings of the value of the use of ICT as learner focus.

Furthermore, educational soundness - the effective integration of ICT can transform pedagogies by empowering teachers to ensure that the use of ICT adds value to the intended learning, design learning programs that ensure the integrity of the learning area and the inclusion of all students (icttaskforce@mceetya.edu.au). Scaffold learning using appropriate technologies, content, services and environments and also appraise the effectiveness, efficiencies and ethics of the use of ICT in the design of learning programs.

Also, effective integration of ICT can transform pedagogies by empowering teachers to connect with and learn from colleagues and students and participating in professional learning programs, explore, understand and utilise the potential of ICT in teaching management and administration, appraise pedagogies made possible by new technologies and evaluate, create and shape the development of resources and products. This falls under professional learning.

In addition to professional learning there is diversity (Fontaine, 2000).Effective integration of ICT can transform pedagogies by empowering teachers to make connections with learning goals and prior knowledge, provide culturally diverse perspectives, motivate and support students whose learning is at risk and provide a range of learning experiences, at varying levels of complexity including real and hypothetical problems, simulations, modelling, dialogues and games. Teachers also need to be empowered to use planning tools to connect learning programs with curriculum assessment and reporting frameworks, communicate in ways that cater for the diverse needs of students and their families, share information, practice and understandings across schools and education systems and incorporate learning practices used in the world beyond school. Also in collaboration, effective integration of ICT can transform pedagogies by empowering teachers to work with studies and utilise their expertise to incorporate new technologies to support their learning support and develop collaborative projects which provide opportunities for students to access and interact with community, industry and educational specialists as well as develop partnerships with local and global communities (icttaskforce (a)mceetya.edu.au).

However, Perraton, Robinson and Creed (2001) note that teachers discover a new potential for their work as they explore the opportunities that using ICT in learning provides. Teachers understand that technologies alter and enhance their role and that the possibilities that ICT afford in education are realised through their judgements and work. They engage with the possibilities, increasing portability and user friendliness and opportunity and created by high speed connectivity to worlds beyond the classroom. Thus blended learning environments allow students to take part in both synchronous and asynchronous learning, overcoming barriers of communication, time and distance. This can connect students more closely to communities, significantly reduce the effects of remoteness and engage students disaffected with schooling (Pacey, 1999).

Haddad (2003) contends that ICT can change the way teachers teach and that it is especially useful in supporting more student - centred approaches to instruction and in developing the higher order, skills and promoting collaborating activities, by recognising the importance of ICT in teaching and learning. Majority of countries in the world have provided ICT teacher training in a variety of forms and degrees (Australia's teachers: Australia's future, 2003). Even though many teachers report that they have had adequate training to prepare themselves to use technology effectively in teaching and learning efforts have been made around the world in which countries are effectively using technology to retrain teachers and are training teachers to use technology as tools for enhancing teaching and learning. Professional development of teachers and support staff is essential. Australia's teachers: Australia's future (2003) recommends all teacher education programs prepare prospective teachers for the digital age and that opportunities be created for teachers to upgrade their ICT knowledge and skills.

Collis and Jung (2003) have come up with categories for ICT teacher training which include ICT as main content, focus. This approach has an emphasis on teacher training in how to use ICT in the classroom. It addresses issues such as selecting appropriate ICT tools and supporting students in the use of those tools, using ICT to promote learning activities, developing new methods of facilitating learning and evaluating student performance. Secondly ICT is considered as core delivery technology. In this approach ICT is used as the major way of providing the learning experience of teacher training. The content of this approach does not necessarily focus on ICT skill itself but rather covers a variety of ICT applications. The case of the Virtual High School (VHS: http://www.govhs.org/website.nsf) in the USA provides an example of the internet-based ICT teacher training. The VHS has developed two graduate level online professional development courses for teachers of participating high school. Thirdly, ICT is seen as part of content or methods. This approach integrates ICT into 
teacher training to facilitate some aspects of training, one such example of this approach can be found in the school administrators technology integration Resource (http://www.satirritas.org) project a bilingual Canadian initiative which provides tools and resources to help school administrators successfully integrate ICT into curriculum in their schools. Finally, ICT is taken as a facilitating or networking technology. ICT as core technology for delivering teacher training can be found in limited contexts, there are many examples of ICT particularly internet and web-based communication technologies being used to support teachers' ongoing professional development and networking. An example of this is the UK virtual Teacher Centre (http://vtc.gov.uk) website which provides a career development area which provides a variety of learning and teaching resources and links to support teachers' continuing professional development.

Jung (2001) notes that, most of the ICT teacher training programs in the 1990s focused on ICT use as the main training content. The approach has an emphasis on teacher training in how to use ICT in the classroom. It addresses issues such as selecting appropriate ICT tools and supporting students in the use of those tools using ICT to promote learning activities, developing new methods of facilitating learning and evaluating student performance.

\subsection{The implementation of computer based MIS in schools}

Davis and Ellison (1997) state that, the manner in which information flows is determined by the nature of the organisation and its inherent management styles. Computer based MIS is the processing of data into information that is then communicated to a user. This involves cost brought by data collection storage, processing and retrieval, for example there is cost in collecting attendance data. The class teacher can turn this data into information by looking at the pattern of absences of particular individuals. The head can aggregate the data from each class and compare attendance noting any particular variance. The head can aggregate even further to compare with previous years to predict annual figures. The attendance example also highlights the fact that there are different information needs within an organisation. According to beers cybernetics model (Beer, 1996) says that the management process consists of five levels which are operational, coordination, control, planning and evaluating. Within the school it is possible to see these five levels at work. Data flows between these levels. Rose and Mahlek (2000) note that in a school exhibiting the characteristics of linear organisation information flows in a very narrow, well defined channels, policies are formulated by the governors who interface with the external world, plans are made on targets set by the senior or strategic team, which are then communicated through the system. This leads to effect computer - based MIS because there is a process to be followed.

\subsection{Advantages and limitations of computer MIS}

Nearly every school has a computer in the area of study. It reveals that computer plays a crucial role. Computers are readily adapted to provide selected types of information same time and relieve programmes of considerations effort in data processing. Dorf (1997) notes that up to date information makes it possible to corrective, initiative investigative action or take steps to resolve identified difficulties before they magnify. However the usefulness of a computer depends on what programme designers apply to its capabilities in the form of intelligence and creativity. Generally computers are important tool in the management of information system. The administrators use the computers to collect disseminate, store and communicate information. Therefore the limitations of computers should be considered in developing or expanding their use in the management and information system. Davis and Allison (1999) suggest that school heads should be aware of the systems and technological problems of the systems such as human errors, lack of knowledge, resistance to change and natural disasters.

\section{Conclusion}

This paper reviewed literature in respect of the use of smart phones in schools, computer use by schools and learners, teacher competence in use of ICT and the implementation of computer based MIS in schools, advantages and disadvantages of the use of ICT.

\section{References}

[1]. Barber, B (1995) Jinad vs Mcworld: How Globalism and Tribalism are reshaping the world, New York: Random house

[2]. Barners, D: An Intergrated Perspective Operations management, London : Beadford row

[3]. Beer, M (1996) Decision and Control, New York: Willey.

[4]. Bowes, J (2003). The emerging repertoire demanded of teachers of the future, surviving the transition, retrieved. 13 December 2012 from

[5]. http://cript.com/confpapers/CRPITV23BOWES.pdf

[6]. Carlson, S and Gadio, CT (2002) Teacher professional development in the use of technology in W.D Haddad and a Draxler (Eds) technologies for education: potential, parameters, and Prospects, Paris and Washington DC UNESCO and AED.

[7]. Collis, B. and Jung, I.S. (2003) Uses Of Information and Communication Technologies In Teacher Education. In B. Robinson and C. Latchner (Eds), teacher education through open distance learning, London : Routledge Falmen, 171 -192 
[8]. Davis, G.B. and Ellison, M.H. (1997) Management Information System ( $2^{\text {nd }}$ ed), London. Mcgraw Hill.

[9]. Dolf, R.C. (1991) Introduction to, Computer Science $\left(2^{\text {nd }} E d\right)$ San Francisco

[10]. Fenry B. (2008) "using mobile phones to Augment teacher Learning in Environmental Education in hello: where are you in the landscape of Educational Technology?"

[11]. Fontaine, M (2000) Teacher training with technology. Experience in five country programme Technologia. November / December, $69-71$

[12]. Garura, C, E (2010) "Internet! A friend or foe?"

[13]. Gross L.S (2010) Electronic Media $10^{\text {th }}$ Ed International edition: McGraw Hill.

[14]. Haddad, W.D (2003) Is Instructional technology a must for learning ? Technology (2004) M.L and Article ID

[15]. Haralambos. And Holborn M. (2008) Sociology : themes and perspectives. London : Collins

[16]. Leedy, P.D (1995) Practical research Planning and Design. New York: Mc Millan

[17]. Pritchard, F (2009) Youth and cellphones observations and Explorations, Clarity innovations Inc

[18]. Perraton. H.,Robinson, B., \& Creed, C. (2001) Teacher Education through distance learning: technology curriculum, evaluation, cost, Paris: UNESCO.

[19]. Schaefer R.T. (2010). Sociology. New York, McGrawHill

[20]. Sellion, A.N (2009) Youth and Cellphones, Observations and Explorations, Clarity,Innovations Inc.

[21]. Siddiqui, M.H : 2004 Challenges of Educational Technology. S. B Nangia Apit P coporation. New Delhi.

[22]. http:www.en.wikipedia.org/wki/year 2000 pedagogy accessed 20 December 2012

[23]. vhs:http://www.govhs.org/website 2 Jan 2013

[24]. http:vtc.ngfl.gov.uk accessed 20 December 2012

[25]. ictaskforce@mceetya.eduau accessed 15 Feb 2013 2013-05-31

[26]. hawkoblog - unit/as4blogspot accessed 3 April 2013-05-31

[27]. australia's techers .ministerialcouncil educational training and youth affairs (Australia and New Zealand) accessed 3 April 2013. 